\title{
Studium und Übersetzung der Bibel in Ungarn zur Zeit der Reformation (1540-1640)
}

\section{Heilige Schrift - geheiligte Schrift}

\subsection{Theologie}

Von Beginn an hatte sich die Reformation in Ungarn wie im Rest Europas an die Bibel gebunden: „Mein Gewissen ist durch Gottes Wort gefangen“, wie Martin Luther (14831546) es 1521 auf dem Wormser Reichstag zum Ausdruck brachte. ${ }^{1}$ Diese Selbstbindung führte paradoxerweise zu einer signifikanten Transformation ihrer Determinanten. Was in der Retrospektive des 21. Jahrhunderts auf das „Jahrhundert der Reformation“ ${ }^{\text {" }}$ als ein Lese-, Interpretations- und Rezeptionsprozess des geschriebenen Wortes („Heilige Schrift“) erscheinen mag, erweist sich bei näherem Hinsehen auf die unterschiedlichen Etappen der Perzeption und Rezeption der Bibel in einem spezifischen historischen Kontext faktisch als Gegenteil: die jeweiligen Leser der Bibel - vom ersten protestantischen Druck einer ungarischen Bibelübersetzung bis hin zur Veröffentlichung der ersten römisch-katholischen ungarischen Bibel - näherten sich dem Text vom Ausgangspunkt ihrer als ewig und kontextunabhängig angenommenen interpretativen Grundsätze, insbesondere von der Überzeugung einer absoluten Geltung des geschriebenen Wortes.

Die häufig anzutreffende Formulierung, die Reformation habe die Bibel zur Grundlage des Glaubens gemacht, trifft nur insofern zu, als von Glaube in inhaltlicher Hinsicht die Rede ist: sobald der Begriff des Glaubens im Sinne des Heilserwerbs in den Blick gerät, kehrt sich das Verhältnis um: es ist der Glaube, von dem ausgehend biblische Kritik geübt wird - und nicht umgekehrt. Das Prinzip „sola fide“ geht, anders formuliert, dem Prinzip „,sola scriptura“ voraus, wie es in einem Gemälde aus der Lutherischen Pfarre Jerking (Györköny, Landkreis Tolna) treffend ins Bild gesetzt ist: ${ }^{3}$ gezeigt werden Luther und Friedrich der Weise (1463-1525) zuseiten der Bundeslade, welche auf einem als „Glauben“ bezeichneten Fels ruht. Die Bibel befindet sich auf der

Übersetzung: Tobias Jammerthal.

1 R. H. Bainton, Here I stand. A Life of Martin Luther (Nashville, 1980 [1950]), 185; L. D. Mansch und C. Peters, Martin Luther. The Life and Lessons (Jefferson, NC, 2016), 119.

2 P. Ács und H. Louthan, „Bibles and Books. Bohemia and Hungary,“ in A Companion to the Reformation in Central Europe, Hg. H. Louthan und G. Murdock (Leiden/Boston, 2015): 402.

3 J. Heltai und B. Gáborjáni Szabó, Hg., Biblia Sacra Hungarica. ,A könyv, mely örök életet ád“ [Biblia Sacra Hungarica. Das Buch, das ewiges Leben bringt], Exhib. Cat. Hungarian National Széchényi Library, 21.11.2008 - 29.03.2009 (Budapest, 2008), 158. 


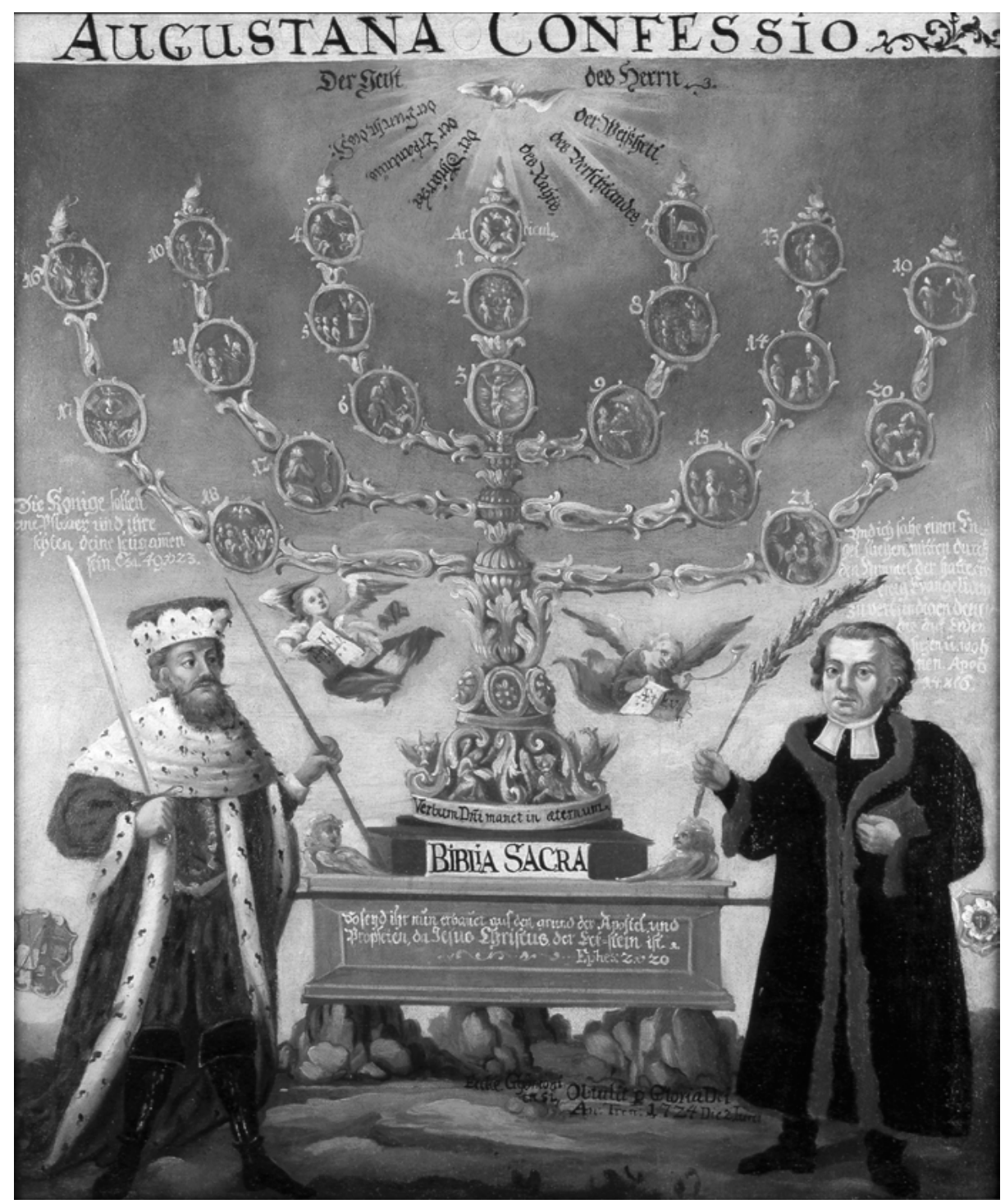

Abb. 1 Anonym, Allegorie der Confessio Augustana mit Friedrich dem Weisen und Martin Luther, um 1724, Öl auf Leinwand, Kopie eines Stichs von Jacob van der Heyden (1573-1645) (Luther-Museum Budapest)

Lade, auf ihr steht eine Menorah als Symbol der Confessio Augustana und der unterschiedlichen Glaubenswege.

Ihrer religiösen Zugehörigkeit ungeachtet erblickten die meisten Bibelleser der Reformationszeit in der Heiligen Schrift das im Glauben erschließbare Wort Gottes. Erst die Formula Consensus Helvetica von 1675 formulierte, dass die Bibel wortwörtlich diktiert worden sei und dehnte somit die Inspiriertheit des Bibeltextes nicht nur auf 
die Konsonanten, sondern sogar auf die masoretische Vokalpunktation des hebräischen Textes des Alten Testamentes aus. ${ }^{4}$ Der transylvanische protestantische Bibelübersetzer István Gyulai formulierte 1551 entsprechend: „solche Kenntnis kam nicht von einem Manne noch von einem Engel, sondern von Gott dem Allmächtigen und allein Weisen selbst. “5 Ähnlich heißt es 1626 in der Vorrede zur jesuitischen Bibelübersetzung von György Káldi (1573-1634), dass der Heilige Geist der „Schöpfer der Heiligen Schrift“6 sei, und der Protestant Gáspár Károlyi (1529-1591) erläutert in der Widmungsvorrede zu seiner Vizsoly-Bibel von 1590, dass Gott bis zum Auftreten des Mose „aus seinem eigenen heiligen Munde“ mit den Erzvätern geredet habe. Danach habe er sich Mose und den Propheten und schließlich „durch seinen Sohn“ geoffenbart. ${ }^{7}$ Gott spricht also, schreibt anschließend selbst auf die Steintafeln des Mose und lässt erst danach seine „Worte“ durch die vom Heiligen Geist inspirierten Propheten und Evangelisten niederschreiben.

Dass das aus dem Griechischen übernommene Lexem „Wort Gottes“ nicht einfach ein Buch bezeichnet, war einem jeden, der mit der Bibel einigermaßen vertraut war, selbstverständliche Tatsache: der berühmte Johannesprolog bezeichnet nach Auffassung seiner meisten Interpreten eine ewige Person („Hypostasis“) des einen und unteilbaren Gottes als das Wort, ${ }^{8}$ weswegen das Wort einerseits der Sohn Gottes und andererseits Gottes Schöpferwort (,,alle Dinge sind durch dasselbe gemacht“), aber auch die konkrete, durch den Heiligen Geist, der nach der bekannten Erweiterung des Nicaeno-Constantinopolitanischen Glaubensbekenntnisses aus dem Vater ,und dem Sohn“ (filioque) hervorgeht, ${ }^{9}$ gewirkte Kunde von Gott durch Propheten und Evangelisten als Sprecher oder besser Schreiber des Wortes Gottes bezeichnen kann. Die erschaffene Welt und die Bibel sind insofern beides „Bücher“ von Gott, Ausdruck seines Wortes, wie alle ungarischen Bibelübersetzer betonen. Káldi führt Paulinus von Nola (353/54-431) als Beispiel an, der in seiner Kirche je ein Tabernakel für die Hostien und ein Tabernakel für die Heilige Schrift gehabt habe, ${ }^{10}$ um die doppelte (mystische und konkrete) Gegenwart des Wortes im Leben der Gemeinde zu verdeutlichen.

Luthers (von den ungarischen Reformatoren übernommener) Ausdruck, „durch das Wort Gottes gebunden“ zu sein, hatte somit einen mindestens dreifachen Aussagegehalt: Bezugspunkt konnte einerseits Christus als Gottes Wort sein, insofern

4 J. L. Borges, „A Defense of the Kabbalah,“ in Selected Non-Fictions, Ders., Hg. E. Weinberger: 83. 5 G. Heltai et al., Biblia [Die Heilige Bibel], 7 Bde. (Kolozsvár, 1551-1565); E. Zvara, Hg., ,Az keresztyén olvasóknak‘. Magyar nyelvü bibliafordítások és -kiadások elöszavai és ajánlásai a 16-17. századból [,An die christlichen Leser. Vorworte und Widmungen in ungarischen Bibelübersetzungen und -editionen im 16. und 17. Jahrhundert] (Budapest, 2003), 72.

6 Ebd., 212.

7 Ebd., 175.

8 R. Bultmann, Theology of the New Testament, übers. v. Kendrick Grobel (Waco, TX, 1951), 2:21-25.

9 A. E. Siecienski, The Filioque. History of a Doctrinal Controversy (Oxford, 2010).

10 Zvara, ,Az keresztyén olvasóknak‘, 211. 
Luther und seine ungarischen Nachfolger sich als Jünger Christi verstanden. Zweitens war es möglich, das „Wort“ als die Heilige Schrift zu verstehen, weil und insofern damit der Überzeugung, in ihr Gottes niedergeschriebene Botschaft zu finden, Ausdruck verliehen wurde, und drittens konnte das „Wort“ als unmittelbare Eingebung des Heiligen Geistes an seine Propheten, als deren Erben im Hören auf das Wort sie sich verstanden, aufgefasst werden. Charakteristisch fasst dies András Farkas (Andreas Lupus) in seinem als eines der frühesten und bedeutendsten Werke der ungarischen Reformationsliteratur geltenden Gedicht Über das Jüdische und Ungarische Volk von 1538 zusammen:

Gott sandte uns

Eine Wolke von Weisen und redlichen Lehrern

$\mathrm{Zu}$ predigen uns durch das Wort

Die Rettung durch Jesus Christ, den Gesegneten ... ${ }^{11}$

Die ersten ungarischen Reformatoren, insbesondere der als „Luther Ungarns“ bekannte Mátyás Dévai (gest. 1547), ${ }^{12}$ vertraten zudem den Gedanken des Priestertums aller Gläubigen ${ }^{13}$ - ohne sich zu diesem Zeitpunkt über die Risiken einer die unmittelbare Inspiration betonenden Frömmigkeit im Klaren zu sein.

\subsection{Hermeneutik}

Unstrittig ist, dass die frühe Reformation hinsichtlich ihrer Bibelauslegung zunächst an mittelalterliche Häresien anschloss. ${ }^{14}$ Die Bemühungen des seit 1533 in Wien für seine protestantischen Überzeugungen eingekerkerten Dévai, eine allgemeine Predigtfähigkeit, die er auch auf Frauen ausdehnte, herbeizuführen, rührten an einen wunden Punkt: ${ }^{15}$ die Berechtigung zur Auslegung der Bibel bildete seit langem einen Streitpunkt innerhalb des Christentums. Die mittelalterliche Kirche unterschied zwischen erzählenden und moralisch erziehenden Passagen der Heiligen Schrift (,aperta“) und den als „profunda“ bezeichneten dogmatisch wichtigen Bestandtei-

11 B. Varjas, Hg., Balassi Bálint és a 16. század költői [Bálint Balassi und die Dichter des 16. Jahrhunderts] (Budapest, 1979), 1:393.

12 J.-A. Bernhard, Konsolidierung des reformierten Bekenntnisses im Reich der Stephanskrone. Ein Beitrag zur Kommunikationsgeschichte zwischen Ungarn und der Schweiz in der frühen Neuzeit (1500 -1700) (Göttingen, 2015), 188-206.

13 Z. Csepregi, A reformáció nyelve. Tanulmányok a magyarországi reformáció első negyedszázadának vizsgálata alapjân [Die Sprache der Reformation. Studien zur Reformation im Königreich Ungarn im ersten Viertel des 16. Jahrhunderts] (Budapest, 2013), 228-238.

14 A. J. Hauser und D. F. Watson, A History of Biblical Interpretation, Bd. 2: The Medieval through the Reformation Periods (Grand Rapids, MI/Cambridge, UK, 2009), passim.

15 Csepregi, A reformáció nyelve, 229-230. 
len. ${ }^{16}$ Während erstere keinerlei Restriktionen unterlagen, war die Auslegung letzterer ebenso wie die Kommunion unter beiderlei Gestalt ein Privileg des geweihten Priesters, woran sich Häretiker stießen, die darum nicht zufällig auf dem ganzen europäischen Kontinent Buch und Kelch als Symbole verwendeten. ${ }^{17}$ Um ihren Predigern die freie Auslegung des Wortes Gottes zu erleichtern, übersetzten sie die Bibel in ihre jeweilige Volkssprache - wie auch die protestantischen Bibelübersetzungen das Wort „frei“, also ohne die Notwendigkeit eines menschlichen Mittlers, nicht in erster Linie aus Gründen der besseren Lesbarkeit, sondern zur Beförderung der Predigt darboten. Und auch mit der auf der Bestreitung der Behauptung, dass die in göttlicher Vollmacht gesprochenen Worte des geweihten Priesters eine Substanzveränderung der Elemente von Brot und Wein zur Leib und Blut Christi herbeiführten, beruhenden Auslassung der mit der Transsubstantiation $\mathrm{zu}$ verbindenden Gesten im protestantischen Abendmahlsgottesdienst konnten die Protestanten an mittelalterliche häretische Bewegungen anschließen.

Von der von Dévai geforderten praktischen Realisierung des Priestertums aller Gläubigen und der freien, geistgewirkten Auslegung der Bibel ließen sich die Reformatoren durch das europaweite Auftreten von als revolutionär empfundenen täuferischen Bewegungen, welche die radikal interpretierte Heilige Schrift in teilweise blutige Taten umsetzten, ${ }^{18}$ schnell abbringen. Ungarn indes wurde von diesen Konflikten nur am Rande, aber dennoch ausreichend berührt, ${ }^{19}$ um hinfort größere Vorsicht nahezulegen. Die Herausforderung für die Reformatoren bestand darin, die Freiheit der Bibelauslegung nicht aufzugeben, ohne zugleich darauf zu verzichten, ungezügelten Auslegungsansätzen gegenüber ein gewisses Maß an Regelhaftigkeit einzufordern. Die Widmungsvorrede der Vizsoly-Bibel fasst daher mehrere Jahrzehnte vorsichtiger protestantischer Hermeneutik wie folgt zusammen: „Nicht jede Auskunft aus jedermanns Munde sollen wir annehmen, wir sollen sie vielmehr an den Schriften der Apostel und Propheten messen, wie der Heilige Geist es uns gebietet.“ Die dahinterstehende Aussage ist eindeutig: da der Heilige Geist sich selbst erklärt, können weder Engel noch Teufel noch Synoden die Bibel auslegen - es ist letztlich Christus selbst, der die Heilige Schrift erleuchtet, da, wie Károlyi den Evangelisten Johannes zitierte, niemand außer dem Sohn Gott je gesehen habe. ${ }^{20}$

In der interpretatorischen Praxis bedeutete dies die Wahrnehmung der dogmatisch relevanten Passagen (profunda) des Alten Testaments durch den Spiegel des Neuen Testaments. Gyulai, ein Mitglied der Übersetzergruppe um Gáspár Heltai

16 J. Le Goff, Saint Francis of Assisi (London/New York, 2004), 10.

17 Th. A. Fudge, Jan Hus. Religious Reform and Social Revolution in Bohemia (London/New York, 2010); N. Nowakowska, „Reform before Reform? Religious Currents in Central Europe, c. 1500,“ in A Companion to the Reformation, Louthan und Murdock: 121-143; Ph. Haberken, „The Lands of the Bohemian Crown. Conflict, Coexistence/the Quest for the True Church,“ in ebd., 11-39.

18 A. Hamilton, The Family of Love (Cambridge, 1981), 14-17.

19 Csepregi, A reformáció nyelve, 187-193.

20 Joh 1,18; Zvara, ,Az keresztyén olvasóknak‘, 176. 
(1520 - 1574), betont, dass die ersten Worte der Genesis als ein Zeugnis für die Trinität zu verstehen seien, „denn, der die Welt erschuf, ist der Vater, das Wort, welches er sprach, ist - wie St. Johannes lehrt - der Sohn, und die Seele Gottes, welche über den Wassern schwebte und ihm Leben gab, ist Gott der Heilige Geist, der aus dem Vater und dem Sohn hervorgeht." ${ }^{21}$ Die figurative protestantische Auslegung zahlreicher alttestamentlicher Texte, insbesondere der Psalmen, des Hohenlieds, des Jonabuches, des Danielbuches oder des Buches des Propheten Ezechiel, aber auch der neutestamentlichen Johannesoffenbarung als Verheißung von Zukünftigem wandte letztlich die als „Pesher“ („Erfüllung“)22 benannte jüdische Auslegungsmethode an, welche sich in der Alten Kirche besonderer Beliebtheit und Verbreitung erfreut hatte (die Auslegung der Johannesoffenbarung gehörte $\mathrm{zu}$ den beliebtesten hermeneutischen Aufgaben dieser apokalyptisch sensiblen Zeit). ${ }^{23}$ Die auch von den Autoren des Neuen Testaments gebrauchte jüdische Auslegungsweise biblischer Texte entwickelte sich in jüdischer wie christlicher nachbiblischer Hermeneutik weiter zur Auffassung vom vierfachen Sinn der Heiligen Schrift: man unterschied literale (historische), moralische, allegorische und anagogische (mit Blick auf das Kommende) Bedeutungsebene. Die scholastische Bibelauslegung gründete sich ebenfalls auf die Lehre vom vierfachen Schriftsinn, ${ }^{24}$ wie Dante Alighieri (1265-1321) sie im Bereich der literarischen Ästhetik anwandte, ${ }^{25}$ woraus Coluccio Salutati (1331-1406) sie mit der Bemerkung, Gott sei der größte Dichter, ${ }^{26}$ und die Bibel sei nicht „historia“, sondern „fabula“ ${ }^{27}$ da ihre tiefere Bedeutung wie die poetischer Werke in allegorischer Weise darzulegen sei, wiederum in die Theologie zurückführte.

Ungeachtet dessen beziehen alle im reformatorischen Kontext entstandenen Bibelübersetzungen Stellung gegen diejenigen, welche „im gesamten Alten Testamente geistlichen Sinn suchen.“28 Protestanten zeigten sich bemüht, ungebremste Allegorese und „Origenisiererei“ - benannt nach dem als Erfinder dieser Methode geltenden alexandrinischen Theologen Origenes (ca. 185-254) -, welche auf dem vierfachen

\section{Ebd., 81.}

22 G. Vermes, The Changing Faces of Jesus (London, 2000), passim.

23 C. L. Beckwith, Hg., Reformation Commentary on Scripture. Old Testament, Bd. 12: Ezekiel, Daniel (Downers Grove, IL, 2012); S. Bene, „Ratio temporum. Dániel próféta és a magyar történetírás [Ratio temporum. Der Prophet Daniel und die ungarische Historiographie], “ in Clio inter arma. Tanulmányok a 16-18. századi magyarországi történetírásról [Clio inter arma. Studien zur ungarischen Historiographie vom 16. zum 18. Jahrhundert], Hg. G. Tóth (Budapest, 2014): 87-116; S. Öze, Apocalypticism in Early Reformation Hungary (Budapest/Leipzig, 2015).

24 P. Ács, „,Én fiam vagy, Dávid ...'A historikus értelmezés korlátai a 2. zsoltár unitárius fordításában [,Du bist mein Sohn, David ... Grenzen der historischen Interpretation bei der unitarischen Übersetzung des Psalms 2],“ Irodalomtörténeti Közlemények 111 (2008): 632-644.

25 Ch. S. Singleton, „Allegoria,“ in La poesia della Divina Commedia, Ders. (Bologna, 1990): 17-35. 26 P. R. Blum, Philosophy of Religion in the Renaissance (Farnham, 2010), 65.

27 P. G. Bietenholz, Historia and Fabula. Myths and Legends in Historical Thought from Antiquity to the Modern Age (Leiden, 1994).

28 Zvara, ,Az keresztyén olvasóknak‘, 83. 
Schriftsinn beharrte, ${ }^{29} \mathrm{zu}$ begrenzen. Für Luther und seine ungarischen Parteigänger galten Allegorien als „Hurenbalg, fein geputzt und halten doch den Stich nicht“, ${ }^{30}$ denen gegenüber ausschließlich die auf den „sensus historicus“ bezogene literale Interpretation des Bibeltextes legitim war. Auf den ersten Blick waren damit mit einem Mal Scholastik und Literatur aus dem Blickfeld der protestantischen Schriftausleger verbannt: während Erasmus von Rotterdam (1466-1536) die „copia verborum“ pries, sprach Luther von der „inutilis verborum copia“.31

Gerade angesichts dessen erscheint die Frage naheliegend, wie es möglich war, dass protestantische Bibelausgaben weiterhin Allegorese betrieben, indem sie etwa bestimmte alttestamentliche Passagen als „Verheißungen“ auf das Neue Testament bezogen. Eine Antwort hat wahrzunehmen, dass protestantische Hermeneutik etwa im Falle der als auf Christus bezogen wahrgenommenen prophetischen Messiastexte figurativen Bedeutungsaspekten literale Bedeutung zuzuschreiben bereit war und sie eben nicht als Allegorien auffasste: die Reformation unterdrückte typologisches Denken nicht, sondern integrierte es ausgehend von der Grundannahme einer engen Beziehung zwischen Altem und Neuem Testament in ein hermeneutisches Regelwerk. Eine größere reformationsbedingte hermeneutische Umstellung betraf die Ersetzung der mystischen durch eine prophetische Bedeutungsebene. ${ }^{32}$ Dass es sich jedoch bei der Bibel um einen Text mit einer literalen und einer geistlichen Bedeutungsebene handelte, war in der Reformationszeit unumstritten. Gyulai etwa schreibt: „Darum weiset unser Herr Christus die Juden in die Schrift [das Alte Testament], da diese von ihm zeuget“. ${ }^{33}$

\subsection{Philologie}

Die Gruppe der Übersetzer um Heltai waren sich dessen bewusst, dass ,auch die Türken der Meinung sind, dass das Alkoran genannte Buch die Offenbarung Gottes sei ... und sie sagen auch, dass ... ihre Schriften vom Engel Gabriel von Gott selbst her gebracht worden seien “34 - eine Anspielung auf die muslimische Überzeugung, dass die Offenbarung Gottes auf einen himmlischen Ursprungstext als Mutter des „Buches“ (,Umm-ul-Kitab“) zurückgehen, dessen Abschriften die irdischen Ausgaben sind. ${ }^{35}$

29 H. G. Reventlow, History of Biblical Interpretation, Bd. 3: Renaissance, Reformation, Humanism (Atlanta, 2010).

30 WA TR 1,607,6 (zu Nr. 1219).

31 C. H. Miller und P. Macardle, Hg., Erasmus and Luther. The Battle over Free Will (Indianapolis, IN, 2012), 83.

32 Ács, „,Én fiam vagy, Dávid““: 638.

33 Zvara, ,Az keresztyén olvasóknak‘, 83.

34 Ebd., 77.

35 R. Simon, A Korán világa [Die Welt des Koran] (Budapest, 1987), 79; J. D. McAuliffe, Hg., The Cambridge Companion to the Quran (Cambridge, 2006), 3; Borges, „A Defense of the Kabbalah“: 83. 
Christliche Vorstellungen von der Bibel waren damit in hohem Maße vergleichbar: manche lutherische Theologen etwa rechneten die Heilige Schrift als die Verkörperung des Heiligen Geistes nicht unter die geschaffenen Dinge. ${ }^{36}$ Dass unterschiedliche Strömungen unterschiedliche Auffassungen bezüglich der konkreten irdischen Ausgabe des „himmlischen Originals“ hatten, vermag dabei kaum zu überraschen: während orthodoxe Christen unter Berufung auf das Übersetzungswunder der 70 die Septuaginta für fehlerfrei hielten, ${ }^{37}$ genoss in der westlichen Christenheit - mit den Worten Káldis - „die ,Vulgata Editio“ genannte alte lateinische [Übersetzung]“ höchstes Ansehen, mit welcher es dem Kirchenvater Sophronius Eusebius Hieronymus (347-420) dank des „großen, der Kirche gegebenen Schatzes“ des Heiligen Geistes gelungen sei, die „wahre Bedeutung“ der Heiligen Schrift zu erhalten. ${ }^{38}$ Inzwischen wissen wir, dass diese dogmatisch so wertgeschätzte Bibelausgabe, wie schon der Bibelübersetzer Károlyi vermutete, tatsächlich eine im Paris des 13. Jahrhunderts standardisierte Version der im 9. Jahrhundert durch den karolingischen Gelehrten Alcuin von York (735-804) bearbeiteten Ausgabe darstellt. ${ }^{39}$

Humanistische Bibelgelehrte brachten gegen die der Vulgata zugeschriebene Autorität das lange vernachlässige Studium des Griechischen in Stellung: gleich mehrfach korrigierte Laurentius Valla (1405/07-1457) den Vulgatatext auf der Grundlage seiner ausführlichen Studien griechischer Manuskripte; ${ }^{40}$ Erasmus übersetzte das Neue Testament aus dem Griechischen (Novum instrumentum omne, 1516) ${ }^{41}$ - eine wichtige Grundlage für die Arbeit erasmianischer ungarischer Bibelübersetzer ${ }^{42}$ - und die Schriften von Pico della Mirandola (1463-1494) und Johannes Reuchlin (1455-1522) boten wichtige Hilfsmittel für eine christliche Hebraistik, welche die Lektüre, Untersuchung und Übersetzung des Alten Testaments aus dem Hebräischen ermöglichte. ${ }^{43}$ In Alcalá de Henares erschien mit der Biblia Polyglotta Complutensia (1514-1517) die erste mehrsprachige Bibelausgabe im Druck, ${ }^{44}$ die auch in Ungarn weite Verbreitung finden sollte, und in Löwen wurde mit dem Collegium Trilingue 1517

36 Ebd.

37 N. Fernández Marcos, The Septuagint in Context. Introduction to the Greek Version of the Bible (Leiden, 2000).

38 Zvara, ,Az keresztyén olvasóknak‘, 214.

39 A. Hamilton, „Humanists and the Bible,“ in The Cambridge Companion to Renaissance Humanism, Hg. J. Kraye (Cambridge, 1998): 102.

40 J. Monfasani, „Criticism of Biblical Humanists in Quattrocento Italy,“ in Biblical Humanism and Scholasticism in the Age of Erasmus, Hg. E. Rummel (Leiden, 2008): 15-38.

41 Heltai und Gáborjáni Szabó, Biblia Sacra Hungarica, 148-157.

42 Hamilton, „Humanists and the Bible“: 111-112.

43 A. Coudert und J. S. Shoulson, Hg., Hebraica Veritas? Christian Hebraists and the Study of Judaism in Early Modern Europe (Philadelphia, PA, 2004).

44 E. Rummel, Jimenez de Cisneros. On the Threshold of Spain's Golden Age (Tempe, AZ, 1999), 53-65; F. Luttikhuizen, Underground Protestantism in Sixteenth Century Spain. A Much Ignored Side of Spanish History (Göttingen, 2017), 41-43. 
ein Institut zum Studium der drei heiligen Sprachen im Geiste des Erasmus gegründet. $^{45}$

Auch die Bibelübersetzung der ungarischen Reformation wandte sich den antiken Quellen der heiligen Texte zu, um der Aufforderung des Erasmus Folge zu leisten, die Heilige Schrift „jedem Volk in seiner Zunge“ zur Verfügung zu stellen ${ }^{46}$ - freilich vielfach in anderer Weise als die erasmianischen Übersetzungen der ersten Hälfte des 16. Jahrhunderts. ${ }^{47}$ Die um Heltai gescharte Gruppe, aus der die erste fast vollständige ungarische Bibel hervorging, orientierte sich am Übersetzungskonzept Luthers, dessen 1522-1534 entstandene deutsche Bibel sie als autoritatives Vorbild sah. Der Wittenberger Reformator teilte seine Übersetzungsprinzipien in seinen Tischreden mit: „so musten sie den nemen, der sich [...] mitt dem neuen testament reumet“48 Demnach legt Christus selbst die Schrift aus, insofern Theologie, Hermeneutik, Grammatik und Philologie betroffen sind: „da der Heilige Geist nicht in allen Fällen der Grammatik folgt, ... muss die Grammatik stets dem Sinn des Heiligen Geistes folgen“, wie Gyulai es, klar von Luther inspiriert, formulierte. ${ }^{49}$ Die biblische Wissenschaft ist somit nach wie vor „ancilla theologiae“ - eine signifikante theoretische Differenz zwischen humanistischer und protestantischer Bibelwissenschaft anzunehmen, wäre ein Missverständnis. Humanistische Gräzisten, christliche Hebraisten und Protestanten waren sich darin einig, dass die Bibel auf einen himmlischen Urtext zurückgeht; sie unterschieden sich lediglich hinsichtlich der zu dessen Rekonstruktion für geeignet erachteten Methoden. Um die eigenen Überzeugungen zu begründen und die der jeweiligen Gegenseite zu widerlegen, wandte sich ein jeder von ihnen ,ad fontes“. Franzisco Kardinal Jiménez de Cisneros (1436-1517) gibt diesem Programm in seiner Vorrede zur Complutensischen Polyglotte einen charakteristischen Ausdruck: er vergleicht die wahre, lateinische Heilige Schrift (der lateinische Text kommt in dieser Ausgabe zwischen griechischem und hebräischem Text zu stehen) mit dem zwischen den beiden Verbrechern gekreuzigten Herren, welche er mit Synagoge und östlichem Christentum identifiziert. ${ }^{50}$

Die Funktionsweise der theologisch inspirierten Philologie des 16. und 17. Jahrhunderts lässt sich an der Übersetzung eines einzigen Wortes einer einzigen Bibelstelle besonders gut veranschaulichen: seit alters interpretiert die Kirche Psalm 22 als Vorhersage der Kreuzigung Christi. Vers 17 (oder, nach hebräischer Zählung, 16) lautet in der Übersetzung der ungarischen Bibel des Károlyi ${ }^{51}$ ganz ähnlich wie in der Lu-

45 H. de Vocht, History of the Foundation and the Rise of the Collegium Trilingue Lovaniense, 1517-1550, 4 Bde. (Löwen, 1951-1955).

46 Á. Ritoók-Szalay, „Erasmus und die ungarischen Intellektuellen des 16. Jahrhunderts,“ in Erasmus und Europa, Hg. A. Buck (Wiesbaden, 1988): 111-128.

47 Zvara, ,Az keresztyén olvasóknak‘, 125.

48 WA TR 5,218,19f.

49 Zvara, ,Az keresztyén olvasóknak‘, 79.

50 Heltai und Gáborjáni Szabó, Biblia Sacra Hungarica, 188.

51 G. Károlyi, Szent Biblia [Die Heilige Bibel] (Vizsoly, 1590), 1:547r. 
therübersetzung von 1545: „Denn Hunde haben mich vmbgeben / Vnd der bösen Rotte hat sich vmb mich gemacht / Sie haben meine Hende vnd Füsse durchgraben.“

Das Wort „durchbohren“ ([mit Nägeln] durchbohren) ist Gegenstand einer jahrhundertalten Auseinandersetzung zwischen jüdischen und christlichen Bibelübersetzern: die hebräische Bibel liest - in Übereinstimmung mit dem Psalmtext - כארי („kaari“), „wie ein Löwe“. In sämtlichen christlichen Bibelübersetzungen beider Konfessionen in Ungarn wie Europa insgesamt seit Septuaginta und Vulgata wird diese Lesart unter der Annahme, dass jüdische Kopisten die Buchstaben Waw (ו) und כארו Jod (י) in einem einfachen Abschreibfehler verwechselt hätten, durch die Variante („kaaru“, durchbohren) bereinigt. Dass dieses Lexem in der hebräischen Sprache nicht vorkommt, wurde auf christlicher Seite ebensowenig zur Kenntnis genommen wie die Tatsache, dass für die Korrektur zum dann in der Tat „durchbohren“ bedeutenden Lexem כרו (,karu“), das freilich durch kein einziges erhaltenes Manuskript für diese Stelle belegt ist, die Eliminierung des Konsonanten Aleph (א) vonnöten wäre. Christliche Philologen entschieden eine philologische Frage somit dogmatisch, was jedoch mehr als eine bloße Konjektur sein kann: die Übersetzung der Septuaginta

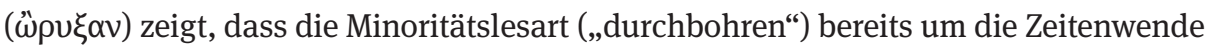
gängig war. ${ }^{52}$ Sie wird - auch wenn nach wie vor starke Argumente für die Mehrheitslesart „wie ein Löwe“ sprechen - offenbar durch ein in Qumran gefundenes Papyrusfragment aus dem 1. oder 2. Jahrhundert gestützt ${ }^{53}$ und begegnet in jeder ungarischen Bibelübersetzung, ob es sich nun um die lutherische Psalmenübersetzung von István Bencédi Székely (1505-1565), ${ }^{54}$ die reformierte Károlyis oder um die unitarische Übersetzung von Miklós Bogáti Fazakas $(1548-1592)^{55}$ handelt, obwohl ihnen allen dieses philologische Problem bekannt war. Der versierte Hebraist Péter Melius (1532-1572) unternahm es sogar, die „Gotteslästerung der Rabbinen“ in einem eigenen Aufsatz über dieses und einige andere textkritische Probleme zu widerlegen. ${ }^{56}$ Angesichts dessen vermag es kaum zu überraschen, dass nur die auf 1624-1629 zu datierende sabbatianischen Psalmenübersetzung des Simon Péchi (1575-1642) aus Respekt gegenüber der jüdischen Tradition dem masoretischen Textbestand entsprechend „wie ein Löwe“ übersetzt. Péchi bemerkt dazu: „da foderunt in keiner jüdischen Schrift begegnet, musste ich bei diesem sensus bleiben. “57

52 H. F. W. Gesenius, Hebrew and Chaldee Lexicon to the Old Testament Scriptures, übers. u. hg.v. S. P. Tregelles (London, 1860), CCCLXXXVIII.

53 P.W. Flint, „The Dead Sea Psalms Scrolls. Psalms Manuscripts, Editions/the Oxford Hebrew Bible,“ in Jewish and Christian Approaches to the Psalms. Conflict and Convergence, Hg. S. Gillingham (Oxford, 2013): $11-34$.

54 I. Székely, Zsoltárkönyv [Der Psalter] (Krakow, 1548), 20r.

55 M. Bogáti Fazakas, Magyar zsoltár [Ungarischer Psalter], Hg. G. Gilicze und G. Szentmártoni Szabó, Nachwort R. Dán (Budapest, 1979), 49.

56 R. Dán, Humanizmus, reformáció, antitrinitarizmus és a héber nyelv Magyarországon [Humanismus, Antitrinitarianismus und hebräische Sprache in Ungarn] (Budapest, 1973), 86; vgl. R. G. Finch und G. H. Box, Hg., The Longer Commentary of R. David Kimhi on the first Book of Psalms (London, 1919), 102-103. 57 S. Péchi, Psaltérium [Der Psalter], hg.v. Á. Szilády (Budapest, 1913), 36. 


\section{Die Ungarische Bibel}

\subsection{Protestantische Übersetzungen}

In der hier zu erörternden Zeitspanne entstanden mehrere ungarische Bibelübersetzungen „im Kontext der Reformation“, ${ }^{58}$ die jeweils ihrer eigenen Herangehensweise hinsichtlich Übersetzung und Erstellung und ihren spezifischen theologischen Konzepten mit jeweils eigenen Zugängen zur Kanonfrage folgten sowie auf spezifische Unterstützerkreise zurückgingen. Die chronologisch erste Stelle nimmt die kommentierte Psalmübersetzung des Székely von 1548 ein, ${ }^{59}$ deren Anspruch, dass in ihr „David weder Hebräisch, noch Latein, noch Griechisch, sondern Ungarisch“ spreche, eindeutig reformatorisch ist. ${ }^{60}$ Wie der Erasmianer János Sylvester (1504-1551) ${ }^{61}$ war Székely ein „homo trilinguis“, der durch seine Kenntnis der drei heiligen Sprachen in der Lage war, aus dem hebräischen Originaltext statt aus der Vulgata zu übersetzen. ${ }^{62}$ Da seine Informationen so gut wie ausschließlich aus der berühmten Basler hebräisch-deutschen Bibelausgabe Sebastian Münsters (1488-1552) von 1534-1535 stammen, ist es nicht ohne weiteres möglich, die Qualität seiner Hebräischkenntnisse näher zu beurteilen. ${ }^{63}$ Wie Münster beabsichtigten Székely und andere christliche Hebraisten, auf der Grundlage des auf Hieronymus zurückgehenden Prinzips der „hebraica veritas“ durch das Studium der hebräischen Quellen auf einen mit christlichen Glaubensüberzeugungen übereinstimmenden Text zu stoßen. ${ }^{64}$ Auch für sie stellte der Antagonismus zwischen Christentum und Judentum einen Ausgangspunkt dar. ${ }^{65}$ Ungeachtet ihrer protestantischen Überzeugung gehörten sie freilich der der Reformation vorangehenden Generation der Humanisten an, weswegen es kaum zu überraschen vermag, dass Luther Münster dafür kritisierte, zu wenig Distanz zu den Lehren gebildeter mittelalterlicher Rabbinen wie Schlomo ben Jizchak, genannt Rashi (1040 - 1105), David ben Josef Kimchi, genannt Radak (1160-1235), und anderen zu halten. ${ }^{66}$ Székely verheißt in der Vorrede seiner Psalmenübersetzung, „bald die ge-

58 J. Horváth, A reformáció jegyében. A Mohács utáni félszázad irodalomtörténete [Im Geiste der Reformation. Die Geschichte der ungarischen Literatur, ein halbes Jahrhundert nach der Schlacht bei Mohács] (Budapest, 1957).

59 Székely, Zsoltárkönyv.

60 Zvara, ,Az keresztyén olvasóknak‘, 70.

61 Die von János Sylvester 1541 in Sárvár-Újsziget veröffentlichte vollständige Übersetzung des Neuen Testaments lehnt sich eng an die Übersetzungen und Kommentare des Erasmus an. Bis zum Ende seines Lebens blieb Sylvester ein Anhänger der altgläubigen Kirche und schloss sich nicht der Reformation an. Vgl. zu ihm Ritoók-Szalay, „Erasmus und die ungarischen Intellektuellen“.

62 Dán, Humanizmus, reformáció, 47-60.

63 Heltai und Gáborjáni Szabó, Biblia Sacra Hungarica, 178-179.

64 E. Rummel, „Humanists, Jews/Judaism,“ in Jews, Judaism/the Reformation in Sixteenth-Century Germany, Hg. D. Ph. Bell und S. G. Burnett (Leiden, 2006): 7-10.

65 See S. P. Markish, Erasmus and the Jews (Chicago, 1986).

66 WA TR 5,218. 
samte Bibel“" zu veröffentlichen, ${ }^{67}$ wozu er nicht mehr kam, auch wenn seine Anmerkungen zu den Psalmen darauf hindeuten, dass er in der Tat eine Übersetzung der Genesis anvisiert hatte.

Die ungeachtet ihrer Verdienste weithin vergessene siebenbändige Ausgabe, welche zwischen 1551 und 1565 durch eine Übersetzergruppe um Heltai in Klausenburg (Kolozsvár, heute Cluj-Napoca in Rumänien) in den Druck gelangte, stellt einen Meilenstein des Bibeldrucks dar. ${ }^{68}$ Dass Heltai, der über eine Druckerei, eine Papiermühle und ein Verlagshaus verfügte, die Erfindung Gutenbergs nach einem in Europa weit verbreiteten Vorbild dazu nutzte, die Bibel der ungarischen Reformation in Umlauf zu bringen, ist offensichtlich. ${ }^{69}$ Das Werk umfasst nahezu den gesamten Bibeltext, die Drucklegung wurde durch Fürst Johann Sigismund Zápolya (1540 - 1571) und andere transylvanische Adlige finanziert, ${ }^{70}$ sollte jedoch nicht nur in Transylvanien, sondern auch im Königreich Ungarn selbst Verbreitung finden, weswegen einige Exemplare keine Widmung an den Fürsten enthalten. Der altgläubige Adlige Lukács Ormosdi Székely im von Transylvanien weit entfernten West-Transdanubien schätzte die Bände sehr, ${ }^{71}$ und auch Calvinisten drängten auf die Vollendung der Heltai-Bibel. Bischof Péter Károlyi begann 1574 mit der Übersetzung der von Heltai und seiner Gruppe nicht übersetzten Bücher des Alten Testaments, sein Tod ein Jahr später verhinderte jedoch die Vollendung des Werks. ${ }^{72}$

Heltais Übersetzergruppe bestand aus Schülern bekannter Bibelgelehrter in Krakau und Wittenberg, darunter einigen qualifizierten Gräzisten und Hebraisten Gergely Vizaknai etwa veröffentlichte auch einen lateinischen Kommentar des Buches Genesis. Im osmanischen Tolna übersetzten Mátyás Tövisi und Imre Szigeti das Buch Sirach ins Ungarische, die Gruppe um Heltai übernahm die Redaktionsarbeit. ${ }^{73}$ Gyulai beschreibt für die Übersetzung des Alten Testaments: „wir folgten der hebräischen Bibel, nahmen aber auch oft Abstand vom hebräischen Wortlaut, damit wir um der eigentlichen Bedeutung willen der ungarischen Sprache folgen konnten. "74 (Die hier anklingenden horatianischen Übersetzungsgrundsätze begleiten die Geschichte der

67 Zvara, ,Az keresztyén olvasóknak‘, 70.

68 Heltai, Biblia.

69 Heltai und Gáborjáni Szabó, Biblia Sacra Hungarica, 166-169.

70 M. Balázs, „Heltai Gáspár zsoltárfordításáról [Über die Pslamenübersetzung von Gáspár Heltai],“ in Biblia Hungarica Philologica. Magyarországi Bibliák a filológiai tudományokban [Biblia Hungarica Philologica. Philologische Studien zu gedruckten Bibeln in Ungarn], Hg. J. Heltai (Budapest, 2009): 55. 71 F. Szakály, „A magyar nyelvü bibliafordítás terjedéséhez [Der Vertrieb ungarischer Bibelübersetzungen],“ in Müvelődési törekvések a korai újkorban. Tanulmányok Keserü Bálint tiszteletére [Kulturelle Unternehmen in der Frühen Neuzeit. Studien zu Ehren von Bálint Keserü], Hg. M. Balázs et al. (Szeged, 1997): 545-554.

72 Vgl. P. Károlyi, Az halálról, feltámadásról és az örök életről hasznos és szükséges könyvecske [Nützliches und notwendiges Büchlein über Tod, Auferstehung und ewiges Leben] (Debrezin, 1574).

73 G. Kathona, Fejezetek a török hódoltságkori reformáció történetéböl [Einige Kapitel der Reformationsgeschichte im osmanischen Ungarn] (Budapest, 1974), 27-29.

74 Zvara, ,Az keresztyén olvasóknak‘, 79. 
ungarischen Bibelübersetzungen durchgängig.) Diese Übersetzungsmethode und die dabei eingenommene theologische Perspektive befand sich im Einklang mit den Ansichten Luthers und seiner Bibel. ${ }^{75}$ So unterscheidet etwa Heltai klar zwischen dem Wort Gottes und literarischem Stil: „Es ziemt sich nicht, dass wir diese Bücher und Erzählungen als solche Fabeln oder Schriften, die menschlichem Gefühl entwachsen sind, erachten ... sie sind nicht eitle Wortklaubereien noch einfältige Fabeln, sondern die wahren Worte des Herrn, des gelobten. “76 Heltai selbst übersetzte den von Luther als „kleine Bibel“ bezeichneten Psalter ins Ungarische. Ein Vergleich mit der früheren Übersetzung von Székely ist instruktiv: an die Stelle humanistischer Philologie und ihrer Einsichten ist Luthers eindeutige Botschaft getreten: „In diesem Buch vergleicht der Heilige Geist die beiden Länder unseres Herren Jesu Christi und des Heiligen Königs David."77 Die ganze Folge der Bücher vermittelt Luthers Evangelium an die Ungarn: „lass diese Welt toben und feiern: sie wird bald enden.“

Unterdes veränderten sich die äußeren Bedingungen der Reformation in allen drei Teilen Ungarns: im Laufe der 1560er Jahre gewannen Anhänger der Schweizer Reformation in vielen Gebieten an Unterstützung, während es in den 1570er Jahren, vor allem in Transylvanien und im osmanischen Teil Ungarns die Antitrinitarier waren, die eine wichtige Rolle spielten. Unter diesen sich schnell verändernden Kontexten entstand die Bibelübersetzung des einflussreichen calvinistischen Pfarrers von Debrezin, Péter Melius. Mit János Enyingi Török (1529-1562) war der Grundherr von Debrezin sein wichtigster finanzieller Förderer. Auch Melius wollte die gesamte Bibel übersetzen, kam jedoch lediglich dazu, die Samuelis- und Königebücher (1565), das Buch Hiob (1565) und das Neue Testament (1567) zu übersetzen, wobei sich von letzterem keine Exemplare erhalten haben. Bei einem Blick auf die Übersetzung des Melius fällt zunächst auf, ${ }^{78}$ dass der eigentliche Bibeltext unter der Fülle von Marginalien beinahe versteckt wirkt, wodurch der Eindruck entsteht, dass das Wesentliche am Rand und nicht im Text selbst zu finden sei. Melius als engagierter Reformator machte von der Bibel Gebrauch als Waffe in seinem Kampf gegen Römisch-Katholische, Antitrinitarier und Täufer: „Siehe, die Gnade des Herren kommt zu uns Tag für Tag, sein Reich wird auferbaut und das Reich des Satans vernichtet. Von Tag zu Tag nimmt zu der Glanz des Wortes Gottes und seine Klarheit“, wie Melius formuliert. ${ }^{79}$ Dabei erscheint es offensichtlich, dass für den Pfarrer von Debrezin nicht länger die Hermeneutik im Sinne einer Einführung in die Bedeutung der Bibel, sondern die Exegese im Sinne einer Auslegung oder Überführung der hermeneutischen Einsichten in die Herausforderungen des täglichen Lebens im Mittelpunkt steht. Seine Randkommentare erweisen sich daher als wichtige Quellen für das ungarische Alltagsleben der Zeit. Melius hatte sich intensiv mit der Exegese befasst und Kommentare zu na-

75 Balázs, „Heltai Gáspár zsoltárfordításáról“: 79.

76 Zvara, ,Az keresztyén olvasóknak', 131.

77 Ebd., 121-122.

78 Heltai und Gáborjáni Szabó, Biblia Sacra Hungarica, 170.

79 Zvara, ,Az keresztyén olvasóknak‘, 170. 
hezu allen biblischen Büchern verfasst; seine Übersetzungsbemühungen reihen sich in diese exegetischen Anstrengungen ein. Hebräische Texte übersetzte er ausgehend von den Editionen, lateinischen Übersetzungen und Kommentaren Münsters, des Vatablus (François Vatable, 1495-1547) und den Genfer Übersetzern ins Ungarische, ${ }^{80}$ auch die Kabbalah als wichtiges Zeugnis nachbiblischer jüdischer Lehre benutzte er (selbstverständlich unter christlichen Voraussetzungen), indem er beispielsweise ihre Zahlenlehre dafür einsetzte, verborgene Botschaften des Bibeltextes ans Licht zu bringen - etwa, dass es sich beim in apokalyptischen Texten vorkommenden ,apokalyptisch Tier“ um den Papst handle. An den Diskursen eidgenössischer Theologen nahm Melius auf prominenter Ebene teil, einem seiner Briefe an Bullinger lag eine inzwischen verloren gegangene Abhandlung bei, in der er die textkritische Argumentation der sonst von ihm hoch geschätzten Exegeten Joseph Albo (1380-1444), David ben Josef Kimchi und anderer zu Fragen wie den oben anhand von Psalm 22 dargestellten zu widerlegen unternahm. Auf den Spuren seines Wittenberger Lehrers Johannes Forster (1496-1558) versuchte Melius somit, von der „hebraica veritas“ zu lernen und schloss doch zugleich jüdische Ansätze aus. Gott begegnet des Öfteren als „Jahwe Elohim“, auch wenn es Melius bewusst war, dass der erste hebräische Gottesname eine Singular- und der zweite eine Pluralform darstellt: charakteristisch für Melius ist, dass er die Kombination als „Heilige Dreifaltigkeit, ein Gott“ ins Ungarische übertrug. ${ }^{81}$

Die Übersetzung des Neuen Testaments durch Tamás Félegyházi (1540-1586) erschien 1586 in Debrezin. ${ }^{82}$ Félegyházi, ursprünglich ein reformierter Lehrer und enger Mitarbeiter des Melius, verließ Debrezin 1570 mitsamt seinen Schülern in Richtung des antitrinitarischen Klausenburg, ${ }^{83}$ nur, um im Folgejahr erneut nach Debrezin und zu Melius zurückzukehren, dem er nach dessen Tod im dortigen Pfarramt nachfolgte. Seine zeitgenössisch weit verbreitete Übersetzung, die inzwischen fast in Vergessenheit geraten ist, atmet den Geist des Calvinismus: wie Melius stellt er reiches exegetisches Material in Form von Randbemerkungen zur Verfügung, dessen Umfang immer wieder den des auf der jeweiligen Seite befindlichen Bibeltextes übertrifft. Die Quellen seiner Übersetzung konnten bisher nicht in ausreichendem Maße ermittelt werden; angesichts des hohen Interesses dieses gelehrten Theologen an den Werken des Genfer Reformators Theodor Beza (1519-1605) erscheint es naheliegend, dessen - dezidiert als Ersatz für die inzwischen verdächtig gewordene Arbeit des Erasmus konzipierte - lateinische Übersetzung des griechischen Neuen Testaments (erste Auflage Genf, 1556) ${ }^{84}$ und die ihr beigegebenen Ma-

80 J. P. Vásárhelyi, „Robert Estienne magyarországi hatása [Der Einfluss von Robert Estienne in Ungarn],“ in Biblia Sacra Hungarica, Heltai und Gáborjáni Szabó: 65-75.

81 Dán, Humanizmus, reformáció, 71-87.

82 Heltai und Gáborjáni Szabó, Biblia Sacra Hungarica, 172-173.

83 Horváth, A reformáció jegyében, 301.

84 B. Roussel, „Le Novum Testamentum de Théodore de Bèze. L'édition, la traduction, ez l'annotation de l’Épître de Jude,“ in Theodore de Bèze, 1519-1605, Hg. I. D. Backus (Genf, 2007): 185-194. 
terialien als Ausgangspunkt der Übersetzung anzunehmen. Auch Félegyházi starb vor der Vollendung seines Übersetzungsprojekts; sein Kollege György Gönci unternahm es, die Lücken zu schließen, indem er beispielsweise den Judasbrief übersetzte und ein Vorwort zur Verfügung stellte (während die Kommentierung der Johannesoffenbarung wohl nicht von ihm stammt).

Vier Jahre später, 1590, erschien mit der Vizsoly-Bibel unter der Herausgeberschaft des Dekans von Gönc, Gáspár Károlyi, ${ }^{85}$ die beeindruckendste ungarische Bibelübersetzung, ${ }^{86}$ ein von den reichen calvinistischen Adligen András und Gáspár Mágócsy sowie dem späteren Fürsten von Transylvanien, Sigismund Rákóczi (15441608) finanziertes ambitioniertes Unterfangen: Rákóczi hatte den Drucker Bálint Mantskovit (gest. 1596) damit beauftragt, mitsamt seiner Werkstatt von Galgóc (heute Hlohovec/Slowenien) nach Vizsoly umzuziehen, wo er die Bibel veröffentlichen sollte. Der Übersetzungsvorgang nahm etwa 15 Jahre in Anspruch, die Drucklegung erfolgte in den eineinhalb Jahren zwischen Februar 1589 und Juli 1590. Während es sich bei der Übersetzung selbst nicht um das Werk eines Einzelnen, sondern wie bei der Bibelübersetzung Heltais um das einer Übersetzergruppe handelte, lag die redaktionelle Arbeit vollständig bei Károlyi. ${ }^{87}$ Zumindest Teile des Alten Testaments der VizsolyBibel zeigen, dass den Übersetzern die Heltai-Bibel vorlag, wenngleich die beiden Übersetzergruppen unterschiedlich arbeiteten: während Heltai und seine Kollegen tatsächlich als Gruppe gearbeitet hatten, scheint Károlyi die Arbeit unter seinen Mitarbeitern verteilt zu haben. Ein Zufallsfund in den 1980er Jahren förderte eine Seite der Druckvorlage der Vizsoly-Bibel mit den handschriftlichen Korrekturvermerken Károlyis am Rande zutage. ${ }^{88}$ Dieser Fund erwies sich als hilfreich für die Rekonstruktion der unterschiedlichen Phasen der Redaktion und Drucklegung: Károlyi, dessen Vorrede zur Vizsoly-Bibel bereits oben zitiert wurde, nahm im nachtridentinischen Katholizismus vorherrschende Ansichten ins Visier, indem er zahlreiche Argumente ins Feld führte, um die Autorität der Vulgata zu untergraben und ihr ein eindeutig protestantisches Programm von Verständnis und Verwendung der Bibel gegenüberzustellen: ${ }^{89}$ „Ich werde es nie unterlassen, euch zu erinnern, dass es nicht ausreicht, darauf zu hören, was wir hier darlegen: ihr müsst die Bibel auch zu Hause lesen!“90 Da die Vizsoly-Bibel schon durch ihren Umfang und ihr Gewicht weit davon entfernt war, für jedermann erschwinglich zu sein, sollte es noch Jahrhunderte dau-

85 A. Szabó, Hg., Károlyi Gáspár a gönci prédikátor [Gáspár Károlyi, Prediger von Gönc] (Budapest, 1984).

86 Heltai und Gáborjáni Szabó, Biblia Sacra Hungarica, 194-195.

87 A. Szabó, A rejtőzködö bibliafordító: Károlyi Gáspár [Der verborgene Bibelübersetzer Gáspár Károlyi] (Budapest, 2012).

88 A. Szabó, „A Vizsolyi Biblia nyomdai kéziratának töredéke [Ein Fragment des gedruckten Manuskripts der Vizsoly Bibel],“ Irodalomtörténeti Közlemények 87 (1983): 523-527.

89 K. Péter, „Bibellesen. Ein Programm für jedermann im Ungarn des 16. Jahrhunderts, “ in Iter Germanicum. Deutschland und die Reformierte Kirche in Ungarn des 16-17. Jahrhundert, Hg. A. Szabó (Budapest, 1999): 7-38.

90 Zvara, ,Az keresztyén olvasóknak‘, 178. 
ern, bis dieses bedeutsame theoretische Programm in die Tat umgesetzt werden konnte. Die Übersetzergruppe um Károlyi erweiterte die bereits verwendeten Quellen um die neue Übersetzung des Heidelberger Hebraisten Immanuel Tremellius (1510 1580), „der ein geborener Jude ist. “91 Neuere Forschungen konnten in Peter Martyr Vermiglis (1499-1562) kommentierter Übersetzung des Ersten Buches Samuelis die Grundlage der entsprechenden Bestandteile der Vizsoly-Bibel identifizieren. ${ }^{92}$ Károlyi und seine Mitarbeiter führten ihre Leser in einen in zunehmendem Maße vereindeutigten protestantischen Kosmos der Bibel, behielten jedoch auf der anderen Seite bestimmte Traditionen bei: das Buch Esther, dessen Textbestand durch große Unterschiede zwischen seinen hebräischen, griechischen und lateinischen Versionen gekennzeichnet ist, wird zunächst aus dem Hebräischen, danach aus Septuaginta und Vulgata übersetzt, während „Teile unauffindbar blieben“, ${ }^{93}$ wie es eine Marginalie mitteilt. Dies zeigt, dass die zügige Drucklegung in Vizsoly bisweilen auch auf Kosten der Qualität der philologischen Arbeit erfolgte.

Eine erneute Durchsicht dieser Übersetzung entsprechend der zeitgenössischen calvinistischen Standards nahm Albert Szenci Molnár (1574-1634) vor, der die Fehler unter Berücksichtigung der besten ihm zu Gebote stehenden Quellen überarbeitete (erschienen Hanau, 1608; Oppenheim, 1612). ${ }^{94}$ Seine Ausgaben trennten deuterokanonische (oder, in protestantischer Terminologie: apokryphe) Schriften von kanonischen und boten die biblischen Bücher in einer protestantischen Grundsätzen entsprechenden Ordnung. Sie zeigen, dass die Bibelübersetzung der Gruppe um Károlyi fortlaufend entsprechend der jeweils vorherrschenden Tendenzen der protestantischen biblischen Wissenschaft weiterentwickelt und modifiziert wurde. Gleichzeitig wurde die Vizsoly-Bibel nie zur Heiligen Schrift einer einzigen Konfessionskirche, da sie lange Zeit auch von ungarischen Lutheranern verwendet wurde - erst im 18. Jahrhundert kam der Gedanke einer eigenständigen lutherischen Übersetzung auf. $^{95}$

\subsection{Römisch-katholische Übersetzungen}

Die römisch-katholische Kirche hat sich stets gegen die Anschuldigung verwahrt, die Lektüre der Bibel in der Volkssprache zu verbieten. Tatsächlich entsprach es mittelalterlichem Herkommen, dass der Priester bestimmte Bibelstellen auf Ungarisch verwendete: die dreibändige Predigtsammlung des Miklós Telegdi (1535-1586), er-

91 Ebd., 179; Heltai und Gáborjáni Szabó, Biblia Sacra Hungarica, 182-183.

92 M. Imre, A Vizsolyi Biblia egyik forrása: Petrus Martyr [Peter Martyr, One of the Sources of the Vizsoly Bible] (Debrezin, 2006).

93 Károlyi, Szent Biblia, 1:507r.

94 Vásárhelyi, „Robert Estienne“: 70.

95 Z. Csepregi, „Evangélikus bibliafordítások a 18. században [Evangelikal-Lutherische Bibelübersetzungen im 18. Jahrhundert],“ in Biblia Hungarica Philologica, Heltai: 171-184. 
schienen in Wien und Nagyszombat [heute Trnava/Slowakei] 1577-1580, ${ }^{96}$ welche von der Vulgata ausgehende eigene Übersetzungen der Sinn- und Feiertagsperikopen bot, stellte lange Zeit die umfangreichste altgläubige Teilausgabe der Bibel in Ungarn dar. Erst mit den Jesuiten, und somit nach der Klärung der Position der Bibel auf dem Konzil von Trient, veränderte sich die Situation: während die Jesuiten auf den ersten Blick lediglich die Autorität der Vulgata erhalten wollten, beantworteten sie auf den zweiten Blick die protestantische mit einer katholischen Reformation, ${ }^{97}$ wobei sie sich der Argumentationsweise ihrer Gegner bedienten und sie gegen die Protestanten einzusetzen begannen. Das Manuskript der von István Szántó Arator (1540-1612) begonnenen Bibelübersetzung ist verschollen. ${ }^{98}$ Der Erzbischof von Gran, Péter Pázmány $(1570-1637),{ }^{99}$ selbst ein früherer Jesuit, verspottete die protestantischen Bibelübersetzungen, indem er behauptete, dass „neue Übersetzungen nichts anderes als unsichere, unverlässliche und widersprüchliche Grammatikübungen“ darstellten. ${ }^{100}$ In diesem Geist folgte ihm sein jesuitischer Bruder Káldi, der auf der Grundlage der Vulgata eine römisch-katholische ungarische Bibel, die, nachdem sie infolge eines umständlichen römischen Genehmigungsprozesses erst 1626 in Wien gedruckt werden konnte, über Jahrhunderte im Gebrauch sein sollte, erstellte. Unlängst wurden handschriftliche Fragmente dieser Übersetzung entdeckt. ${ }^{101}$ Auch Káldi griff in seiner Vorrede protestantische Übersetzer an. Insbesondere Károlyi und Szenci Molnár warf er vor, dass sie, anstatt Gottes reines und eindeutiges Wort zu übersetzen, willkürlich und selektiv vorgingen. ${ }^{102}$ Besonders geschickt erscheint sein Hinweis darauf, dass sich mit der Meinung der protestantischen Bibelwissenschaftler zugleich die Grundlage der Übersetzung häufig veränderten, weil dieser es ihm ermöglichte, den Versuch zu unternehmen, die offensichtlichen exegetischen Meinungsverschiedenheiten auf protestantischer Seite zu seinem Vorteil auszunutzen. Die Geschichte seiner eigenen Übersetzung ist noch nicht ausreichend erforscht, aber es scheint, dass er nicht die verschollene Arbeit Arators nutzte, sondern eigenständig arbeitete, auch wenn es

96 Heltai und Gáborjáni Szabó, Biblia Sacra Hungarica, 202.

97 M. A. Mullett, The Catholic Reformation (London, 1999).

98 A. Molnár. „A horvát és magyar katolikus bibliafordítás és a római inkvizíció [Die kroatische und ungarische katholische Bibelübersetzungen und die Römische Inquisition Inquisition],“ Magyar Könyvszemle 119 (2002): 24-37.

99 P. Ács, „Historischer Skeptizismus und Frömmigkeit. Die Revision protestantischer Geschichtsvorstellungen in den Predigten des ungarischen Jesuiten Péter Pázmány, “ in Jesuitische Frömmigkeitskulturen. Konfessionelle Interaktion in Ostmitteleuropa 1570-1700, Hg. A. Ohlidal und S. Samerski (Stuttgart, 2006): 279-294.

100 P. Pázmány, Hodogeus (Pozsony [heute Bratislava, Slovakia], 1637); vgl. E. Hargittay, „Pázmány Péter a Szentírásról és az Anyaszentegyházról [Péter Pázmány über die Heilige Schrift und die Mutter Kirche],“ in ,Tenger az igaz hitrül való egyenetlenségek vitatásának eláradott özöne... 'Tanulmányok 16-19. századi hitvitáinkról [Studien zu den theologischen Disputen in Ungarn, 16.-19. Jahrhundert], Hg. J. Heltai und R. Tasi (Miskolc, 2005): 79-84.

101 P. Erdő (ergänzende Bemerkungen), A Káldi-biblia kéziratos töredékei [Handgeschriebene Fragmente der Káldi Bibel], Faksimile (Budapest, 2015).

102 Zvara, ,Az keresztyén olvasóknak‘, 247. 
nicht unplausibel ist, dass es sich bei der von ihm erwähnten „zweihundert Jahre alten“ Teilübersetzung um die mittelalterliche ungarische Bibelübersetzung des Jordánszky-Codexes handelte. ${ }^{103}$ In jedem Fall führte die als altgläubiges Bollwerk gegen die Vizsoly-Bibel konzipierte Káldi-Bibel dazu, dass sich die konfessionelle Trennung zwischen Altgläubigen und Protestanten nun auch im Gebrauch der Heiligen Schrift niederschlug.

\section{Bibel und Literatur}

\subsection{Psalmus Hungaricus}

Im Jahrhundert vor der Reformation blühte in Ungarn eine reichhaltige biblische Literatur in Gestalt von biblischen Erzählungen, Jeremiaden, poetischen Kommentaren und Paraphrasen. Spuren von Bibelrezeption würden sich bei näherem Hinsehen in nahezu dem gesamten erhaltenen literarischen Corpus der ungarischen Sprache finden lassen. Bei Paraphrasierungen biblischer Texte handelt es sich indes um Texte der Frömmigkeit; sie galten zu keinem Zeitpunkt als Heilige Schrift. Anders verhält es sich mit den ungarischen Psalmbereimungen der Reformation. ${ }^{104}$ Im Singen dieser Psalmlieder, das für die Gläubigen selbst als Rezitation göttlich inspirierter Worte galt, verbanden sich im Leben protestantischer Gemeinden Frömmigkeit und die Welt der Bibel aufs Engste; die wichtigsten protestantischen Dichter des 16. Jahrhunderts wie Mihály Sztárai (gest. 1575), Gergely Szegedi, Máté Skaricza (1544-1591) und viele andere trugen dazu bei, dass sich die Zahl der von Gemeinden zu ungarischen Weisen $\mathrm{zu}$ singenden Psalmbereimungen stets vermehrte, bis das Corpus der ungarischen Psalmlieder gegen Ende des Jahrhunderts beinahe den gesamten Psalter umfasste. ${ }^{105}$ $\mathrm{Zu}$ diesem Zeitpunkt standen sie freilich bereits unter Kritik, weil sie sich zu weit vom ursprünglichen biblischen Text entfernt hätten. Imre Újfalvi, Herausgeber eines protestantischen Gesangbuchs (Debrezin, 1602) formulierte: „Vom [biblischen] Text sollen wir nichts wegnehmen, noch ihm etwas hinzufügen - geschweige denn Dinge, die seinem Geiste fremd wären.“ In den Augen eines zunehmend biblizistischen Protestantismus konnten etwa die Eingangs- und Schlussverse der Psalmlieder als nicht nahe genug am Wort Gottes fragwürdig erscheinen: zulässig waren ausschließlich

103 Heltai und Gáborjáni Szabó, Biblia Sacra Hungarica, 128-129.

104 É. Petrőczi und A. Szabó, Hg., A zsoltár a régi magyar irodalomban [Der Psalm in der alten ungarischen Literatur] (Budapest, 2011).

105 L. Bóta, „A magyar zsoltár Szenci Molnár Albert előtt [Ungarische Psalmen vor Albert Szenci Molnár]," in Szenci Molnár Albert és a késö-reneszánsz [Albert Szenci Molnár und die Spätrenaissance], Hg. S. Csanda und B. Keserü (Szeged, 1978): 163-178. 
Vertonungen des Bibeltextes „ohne neue Bedeutungen“, „ohne jedwede Anhängsel“. 106

Die neue reformierte Psalmübersetzung durch Szenci Molnár (Herborn, 1607) wurde mit dem expliziten Anspruch, nichts anderes als „reine“ Lieder entsprechend dem „wahren Wortlaut“ zu enthalten, gedruckt. Szenci Molnár hatte sich aus diesem Grunde für eine Übertragung des Genfer Psalters entschieden, der sich zwar in bester Übereinstimmung mit den zeitgenössischen kanonischen Prinzipien des Calvinismus befand, dessen an den von den französischen Originalmelodien orientierte Art der Versifikation ungarischen Ohren jedoch fremd klang. ${ }^{107}$ Der ansonsten durchaus verdienstvolle Szenci Molnár-Psalter wurde Teil der revidierten „Károlyi-Bibel“ und erreichte so beinahe den Status eines heiligen Textes. Auch wenn der Genfer Psalter den gleichermaßen traditionelleren wie hinsichtlich der Texttreue liberaleren „Psalmus Hungaricus“108 nicht gänzlich aus den calvinistischen Kirchen vertreiben konnte, verstummte doch die freie Stimme des Heiligen Geistes zunehmend, während ungarische Unitarier (einschließlich der zu dieser Zeit noch unitarischen Sabbatianer) auf der Grundlage ihrer weniger calvinistischen Auffassung von der Heiligkeit der Psalmtexte drei vollständige ungarische Übersetzungen dieses biblischen Buches vorlegen konnten. Bogáti Fazakas ${ }^{109}$ und János Thordai (1597-1636) ${ }^{110}$ entwickelten unter Zuhilfenahme beträchtlicher poetischer Freiheit einen ungarischen Psalter anhand von an ungarischen Melodien angelehnten Versformen, während Péchi ${ }^{111}$ für seine Übersetzung der Psalmen aus dem Hebräischen die Erkenntnisse nachbiblischer jüdischer Gelehrsamkeit fruchtbar machte.

\subsection{Im Kontext der „arianischen Bibel“}

Ab den 1570er Jahren gewannen antitrinitarische Strömungen in Transylvanien und im osmanischen Teil Ungarns stetig an Anhängern, was zu scharfen Debatten über dogmatisch relevante Teile der Bibel (profunda) führte, welche die schlimmsten Albträume der altgläubigen Kirche und der humanistischen Bibelwissenschaft zu Leben $\mathrm{zu}$ erwecken schienen. ${ }^{112}$ Ohne sich um die Warnung des (ansonsten hoch geschätzten) Erasmus, dass Theologie nichts für Ungebildete sei, zu kümmern, dis-

106 I. Újfalvi, Keresztyéni énekek [Christliche Hymnen] (Debrezin, 1602), Faksimile mit ergänzenden Bemerkungen von P. Ács (Budapest, 2004), 20-21.

107 I. Bán, „Szenci Molnár Albert, a költő [Albert Szenci Molnár, der Dichter],“ in Szenci Molnár, Csanda und Keserü: 137-153.

108 Psalm 55 in seiner Übersetzung durch Mihály Kecskeméti Vég aus dem 16. Jahrhundert bildet die Grundlage von Zoltán Kodálys berühmter Vokalkomposition „Psalmus Hungaricus“ (1923).

109 Bogáti, Magyar zsoltár.

110 B. Stoll, M. Tarnócz und I. Varga, Hg., Az unitáriusok költészete [Die Dichtung der ungarischen Unitarier] (Budapest, 1967), 156-391.

111 Péchi, Psaltérium.

112 Ács, „,Én fiam vagy, Dávid““: 640. 
kutierte man Fragen der spezielleren Trinitätslehre in Wirtshäusern und auf dem Markt; in Nagyharsány im osmanischen Teil Ungarns konnten die Antitrinitarier ihre Gegner 1574 sogar zu einer öffentlichen Debatte herausfordern. Der antitrinitarische Geistliche György Alviniczi vertrat die Position, dass „wie Pferdekot, so auch die Heilige Schrift auch nützliche Dinge“ enthalte. Da er diese Position auch in Bezug auf den Koran vertrat, wurde er von den Osmanen hingerichtet. Bald danach bekräftigten Antitrinitarier in der Disputation von Buda gegen Calvinisten ihre Auffassung, wonach die Bibel in ihrer derzeit bekannten Form Menschenwerk sei und also gleichermaßen wahre wie falsche Bestandteile enthalte - weswegen es das Beste wäre, im Druckbild von Bibelausgaben menschliche Zusätze in Petit- und göttliche Bestandteile im Großdruck zu bieten. ${ }^{113}$ Unschwer lassen sich hinter diesen Formulierungen die Ansichten von aus Transylvanien geflohenen häretischen Theologen erkennen. Auf einem nur kurz vor den Ereignissen von Buda einberufenen Tag in Torda (heute Turda) hatte der griechische Freigeist Jacobus Palaeologus (1520-1585), ${ }^{114}$ dessen Einfluss auf den ungarischen Unitarismus beträchtlich war, verkündet, dass er im Besitz einer alten Handschrift des Johannesevangeliums sei, nach der Jesus nicht „Gott war das Wort“, sondern „Gottes war das Wort“ gesagt habe. Nach Palaeologus hätten der Trinität anhängende alexandrinische Theologen den originalen Text des Evangeliums bewusst verfälscht. Aus jesuitischen Quellen ist bekannt, dass Pläne zur Einrichtung eines Übersetzungszentrums in Klausenburg unter Führung des Palaeologus bestanden, in der die bekannten transylvanischen häretischen Bibelgelehrten Johannes Sommer und Matthias Vehe-Glirius (1545-1590) dabei zusammenarbeiten sollten, ${ }^{115}$ eine neue lateinische Übersetzung der Bibel anstelle der von Michael Servet (15091553) annotierten Santes Pagninus-Bibel (Lyon, 1542) ${ }^{116}$ und der 1551 in Basel veröffentlichten Bibel des Sebastian Castellio $(1515-1563)^{117} \mathrm{zu}$ erstellen. Bei beiden Übersetzungen handelte es sich um die von Theologen der radikalen Reformation bevorzugte Versionen. Diese „Arianerbibel“ von Klausenburg kam nicht zustande; das tatsächliche Alter des inzwischen verschollenen Manuskripts des Palaeologus ist unbekannt. Darüber hinaus ist zu beachten, dass auch die unitarische Bibelkritik nicht als im modernen Sinne akademisch-objektiv gelten kann, insofern auch sie

113 M. Balázs, Teológia és irodalom. Az Erdélyen kivüli antitrinitarizmus kezdetei [Theologie und Literatur. Der Beginn des Antitrinitarismus außerhalb von Siebenbürgen] (Budapest, 1996), 45-74

114 M. Rothkegel, „Iacobus Palaeologus und die Reformation. Antireformatorische Polemik in der verlorenen Schrift Pro Serveto contra Calvinum," in Radikale Reformation. Die Unitarier in Siebenbürgen, Hg. U. A. Wien, J. Brandt und A. F. Balogh (Köln/Weimar/Wien, 2013): 91-134.

115 A. Pirnát, „A bibliakritika történetének egy ismeretlen fejezete [Ein unbekanntes Kapitel der Bibelkritik],“ in Válogatott eretnekségek. Kiadatlan tanulmányok [Ausgewählte Häresien. Unveröffentlichte Studien], Hg. P. Ács und M. Balázs (Budapest, 2017).

116 N. Fernández Marcos und E. Fernández Tejero, „Pagnino, Servet y Arias Montano. Avatares de una traducción latina de la Biblia Hebrea,“ Sefarad 63 (2003): 283-329.

117 C. Gilly, Spanien und der Basler Buchdruck bis 1600. Ein Querschnitt durch die spanische Geistesgeschichte aus der Sicht einer europäischen Buchdruckerstadt (Basel/Frankfurt a. M., 1985), 193; Ács, „Én fiam vagy, Dávid““: 638. 
ebenso auf dogmatischen Vorannahmen beruhte wie die Arbeit der trinitarischen Theologen. ${ }^{118}$ Wichtiger ist indes, dass Palaeologus und seine Anhänger eine von ihren Zeitgenossen radikal verschiedene Auffassung von der Autorität der Bibel hatten. Die von ihnen anvisierte Bibelausgabe sollte auf der Grundlage allgemein-vernünftiger Annahmen und dogmatisch wie philologisch für authentisch erachteter Quellen erfolgen; eine besondere Heiligkeit maßen sie der Schrift nicht zu. In der Nachfolge von Valla, Erasmus und anderen humanistischen Bibelgelehrten ${ }^{119}$ gingen sie davon aus, dass biblische Philologie sich der gleichen kritischen Kriterien wie die Arbeit mit profanen Texten zu bedienen hätte. Insofern lässt sich die antitrinitarische Bibelkritik als ein wichtiger Schritt darin sehen, die Heilige Schrift nicht mehr nur wie einen literarischen Text zu behandeln, sondern sie auch für einen solchen zu halten.

\subsection{Literarkritik und Bibelwissenschaft}

Auch andere Wege wurden beschritten, um die enge Verbindung zwischen der Entwicklung der Bibelwissenschaften und dem zunehmenden literarischen Reichtum zu ziehen: János Rimay $\left(1570\right.$ - 1631) ${ }^{120}$ erörterte in seiner Vorrede zu einer Sammlung der Liebesdichtung Bàlint Balassis (1554-1594) erstmals allgemein-literaturhistorische Fragen. ${ }^{121}$ Der Text beginnt mit einer ehrgeizigen Zusammenfassung der Entwicklung der Kultur, wobei die Wende vom 15. zum 16. Jahrhundert als Gipfelpunkt umfassender geistlicher Veränderungen apostrophiert wird: „Das Werk der Hände“ oder besser die Künste der „techne“ hatten sich, so Rimay, zu diesem Zeitpunkt weit genug entwickelt, um mit den „Werken der Vorzeit“, des klassischen Altertums, in Konkurrenz treten zu können. Eine ähnliche Entwicklung habe in „den Künsten der Schrift“ stattgefunden: „Wir erleben darin ein wunderbares Geschenk unseres Herren, dass diese Zeiten mit der Fülle seines Wortes, der wahren Kunde seines Heiligen Sohnes und der klaren Offenbarung seines Willens geziert sind.“ Diese Einschätzung kann nur dergestalt verstanden werden, dass für Rimay der Humanismus zur rechten Kenntnis der Bibel und diese ihrerseits zur Reformation führte. Der wahre Glaube als Licht der „himmlischen Leuchte“ trieb die Dummheit vor sich her, die lateinische Sprache wurde in ihren ursprünglichen Zustand zurückversetzt, ,jede Sprache eines Volkes“ gestärkt. Nach Rimay stellt die von vielen Unwissenden kritisierte Liebesdichtung Balassis ein

118 D. A. Frick, Polish Sacred Philology in the Reformation and the Counter-Reformation. Chapters in the History of Controversies 1551-1632 (Berkeley, 1989), 81-115.

119 A. Rabil, Jr., Erasmus and the New Testament. The Mind of a Christian Humanist (Lanham, MD, 1972); Hamilton, „Humanists and the Bible“; Monfasani, „Criticism of Biblical Humanists“.

120 János Rimay (1570-1631) Schüler des wichtigsten ungarischen Renaissancedichters Bálint Balassi (1554-1594) war selbst ein bekannter Poet. Vgl. zu ihm P. Ács, „Ratio e oratio. Tipologie poetiche in János Rimay,“ Annali dell’ Istituto Universitario Orientale di Napoli. Studi Finno-Ungarici 1 (1995): 149 -172 .

121 J. Rimay, Összes müvei [Gesammelte Werke], Hg. S. Eckhardt (Budapest, 1955), 39-40. 
krönendes Ergebnis dieser Erneuerung und Reformation im Einklang mit Gottes Willen dar. Für ihn, so scheint es, stellen sich Humanismus, Renaissance und Reformation, die Entwicklung der Volkssprache genauso wie die der lateinischen Sprache, der biblischen Wissenschaften wie der „bonae litterae“ als Bestandteile eines unaufhaltsamen Fortschritts dar, ${ }^{122}$ der sich freilich nicht im Sinne eines Bruchs mit der Vergangenheit, sondern im Gegenteil als „re-formatio“ im ursprünglichen Sinne des Wortes $^{123}$ vollzog, indem er vergangene Vollkommenheit wiederherstellte. Mit der Erwähnung einer Verbindung zwischen Renaissance und Reformation führte Rimay den Geist des erasmianischen Bibelhumanismus fort. Die Bekehrung der Heiden hatte für Erasmus die Heiligung der Antike insgesamt bedeutet. ${ }^{124}$ Für ihn hatte sich Gott nicht nur den Juden offenbart, sondern den Samen seines Evangeliums im Mutterboden heidnischer Jahrhunderte vor der Geburt Christi eingepflanzt, weswegen auch die klassisch-antike Kultur den Samen einer besseren, christlichen Philosophie enthielt. Christlicher Humanismus war also nach der Überzeugung der Intellektuellen der Renaissance nicht nur die Indienststellung der „artes liberales“ für die biblischen Wissenschaften, sondern vielmehr eine umfassendem Heil dienende reziproke Heiligkeit.

122 Ács und Louthan, „Bibles and Books“: 404.

123 Z. Csepregi, „Die Auffassung der Reformation bei Honterus und seinen Zeitgenossen, “ in Radikale Reformation, Wien, Brandt und Balogh: 1-17.

124 P. Ács, „The Reception of Erasmianism in Hungary and the Contexts of the Erasmian Program. The ,Cultural Patriotism” of Benedek Komjáti, “ in ,Whose Love of Which Country. ' Composite States, National Histories and Patriotic Discourses in Early Modern East Central Europe, Hg. B. Trencsényi und M. Zászkaliczky (Leiden, 2010): 75-90. 